\section{Implications of Changes to the Mefloquine Product Monograph}

In August 2016, Health Canada approved significant changes to the Canadian product monograph for mefloquine, a drug licensed in Canada since 1993 for the prevention and treatment of malaria. These changes mirror those made in the United States and Europe, including the addition of a "serious warnings and precautions" box (or "boxed warning"), which includes warnings that differ substantively in 2 key ways from prior language. ${ }^{1}$

First, the previous product monograph warned only that "If signs of acute anxiety, depression, restlessness or confusion occur during prophylactic use, these may be considered prodromal to a more serious event. In these cases, the drug must be discontinued and an alternative medication should be substituted". ${ }^{2}$ Although this warning remains, the new monograph also warns that mefloquine "should" be discontinued "if psychiatric or neurologic symptoms occur". ${ }^{1}$

Second, the previous product monograph warned only that "Adverse reactions to [mefloquine] may occur or persist up to several weeks after discontinuation of the drug. In a small number of patients it has been reported that dizziness or vertigo and loss of balance may continue for months after discontinuation". ${ }^{2}$ In contrast, the new monograph warns that "Psychiatric symptoms ... on occasions . . . have been reported to continue long after mefloquine has been stopped" and "In a small number of patients it has been reported that dizziness or vertigo and loss of balance may continue for months or years after discontinuation of mefloquine, and in some cases vestibular damage may be permanent". ${ }^{1}$

These changes follow similar changes first made in the United States in 2013. At that time, Health Canada officials determined that no corresponding changes were needed to the Canadian product monograph. ${ }^{3}$ However, in 2014, regulators at the European Medicines Agency (EMA) recommended that substantially similar warnings be added throughout the European medicines regulatory network. ${ }^{4}$ The EMA concluded that there was sufficient evidence "supporting a causal relationship between mefloquine and the occurrence of long lasting and even persistent neuropsychiatric effects" and speculated that these were due to "permanent brain damage". The EMA review noted that no risk factors could be identified for this effect, and that for this reason "only the advice- to stop taking mefloquine if neuropsychiatric reactions or changes to their mental state occur - can be given as a precautionary measure". "Warnings in the United Kingdom and Ireland were subsequently strengthened, emphasizing that even abnormal dreams or nightmares should prompt the drug's discontinuation. $^{5}$

In May 2016, a comparison of international drug safety documentation was published, ${ }^{5}$ which noted significant discrepancies between warnings in the United States, Ireland, and the United Kingdom and warnings in the then-current Canadian product monograph. The subsequently updated Canadian product monograph brought Canadian warnings closer to the international consensus. A Health Canada official would later state that these changes were requested in response to its guidelines for "plain language labelling" published in 2014. ${ }^{3}$

The new warnings have important implications for Canadian pharmacists counselling their patients on the use of mefloquine. In particular, in accordance with warnings in the United Kingdom and Ireland, abnormal dreams or nightmares may now need to be considered among the neurologic and psychiatric symptoms for which discontinuation of mefloquine is recommended. ${ }^{5}$ In contrast, early recommendations for the use of mefloquine by the Canadian Committee to Advise on Tropical Medicine and Travel (CATMAT) described strange dreams and nightmares as "minor side effects", ${ }^{6}$ and the previous Canadian product monograph had stated that "difficulty sleeping, and bad dreams are usually mild and do not cause people to stop taking the medicine". ${ }^{2}$ Today, Roche-which withdrew its branded version of mefloquine (Lariam) from the Canadian market in 2013 but continues to market this product in other countries ${ }^{5}$ - warns that abnormal dreams are "very common" with prophylactic use of mefloquine, and occur in more than $10 \%$ of prophylactic users. ${ }^{7}$

Recommendations by CATMAT acknowledge that if patients experience "psychiatric symptoms, such as acute anxiety, 
depression, restlessness or confusion" during prophylactic use, they should discontinue mefloquine; the recommendations also list "mood changes" among "the most frequent adverse effects" of mefloquine. ${ }^{8}$ Roche notes that symptoms of mood change, including anxiety and depression, occur in 1\%-10\% of those taking the medication, and that other, more severe symptoms, including symptoms of psychosis, occur in between 1 and 10 patients per $1000 .^{7}$ In contrast, influential Canadian authorities have previously claimed, in a figure that continues to be erroneously cited to the present day, ${ }^{3}$ that psychosis and other severe adverse effects occur at a frequency of only 1 in 10000 to 1 in $13000 .^{9}$

Canadian pharmacists should ensure that their patients are properly counselled about the very common occurrence of psychiatric or neurologic symptoms with prophylactic use of mefloquine. Consistent with guidance in the updated Canadian product monograph, pharmacists should also counsel their patients that they should discontinue the drug at the onset of psychiatric or neurologic symptoms, and that they specifically must discontinue the drug at the onset of acute anxiety, depression, restlessness, or confusion, to reduce the risk of potentially permanent adverse effects. Given that many psychiatric or neurologic symptoms will occur only after several weekly doses, ${ }^{10}$ unless a prolonged predeparture trial of mefloquine has been prescribed, such discontinuation will likely require medical intervention while the person is in a foreign country, to obtain alternative antimalarial medication.

\section{References}

1. Mefloquine [product monograph]. Vaughan (ON): AA Pharma Inc; 2016 Aug 4.

2. Mefloquine [product monograph]. Toronto (ON): AA Pharma Inc; 2010 May 27.
3. Standing Committee on Veterans Affairs. Evidence: Thursday, November 3, 2016. 42nd Parliament, 1st Session, No. 29. Ottawa (ON): House of Commons; 2016 [cited 2017 Apr 25]. Available from: www.parl.gc.ca/ HousePublications/Publication. aspx? Language $=\mathrm{e} \&$ Mode $=1 \& \operatorname{Parl}=42 \&$ Ses $=1 \&$ DocId $=8582964$

4. Pharmacovigilance Risk Assessment Committee. Updated PRAC rapporteur assessment report on the signal of permanent neurologic (vestibular) disorders with mefloquine. EMA/63963. London (UK): European Medicines Agency; 2014.

5. Nevin RL, Byrd AM. Neuropsychiatric adverse reactions to mefloquine: a systematic comparison of prescribing and patient safety guidance in the US, UK, Ireland, Australia, New Zealand, and Canada. Neurol Ther. 2016; 5(1):69-83.

6. Committee to Advise on Tropical Medicine and Travel (CATMAT). Canadian recommendations for the prevention and treatment of malaria among international travellers. Can Commun Dis Rep. 1993;19(1):1-6.

7. Lariam [product insert]. Dee Why (Australia): Roche Products Pty Ltd; 2014 Nov 12.

8. Committee to Advise on Tropical Medicine and Travel (CATMAT). Canadian recommendations for the prevention and treatment of malaria. An Advisory Committee statement (ACS). Ottawa (ON): Public Health Agency of Canada; 2014 [cited 2017 Apr 25]. Available from: http:// publications.gc.ca/collections/collection_2014/aspc-phac/HP40-102-2014eng.pdf

9. Keystone JS, Kain K. Mefloquine dangers - fact or fancy? Can J Infect Dis. 1995;6(1):14-5.

10. Stürchler D, Handschin J, Kaiser D, Kerr L, Mittelholzer ML, Reber R, et al. Neuropsychiatric side effects of mefloquine. $N$ Engl J Med. 1990; 322(24):1752-3.

Remington L Nevin, MD, MPH, DrPH

Department of Environmental Health and Engineering Johns Hopkins Bloomberg School of Public Health Baltimore, Maryland

Competing interests: Remington Nevin has served as a consultant and expert witness in legal cases involving claims of antimalarial adverse effects. 